\title{
Antimicrobial Efficacy of Cinnamon Bark Oil on Lactobacillus acidophilus and its Effect on Compressive Strength of Glass lonomer Cement
}

\author{
${ }^{1}$ Sheetal Bhanushali, ${ }^{2} \mathrm{KT}$ Srilatha, ${ }^{3} \mathrm{MS}$ Girish
}

\section{ABSTRACT}

Aim: The aim of this study is to evaluate the minimum inhibitory concentration (MIC) of cinnamon bark oil against Lactobacillus acidophilus and incorporate it in the liquid component of glass ionomer cement (GIC) followed by determination of its effect on the compressive strength.

Materials and methods: Antibacterial effect of various concentrations of cinnamon bark oil was evaluated using broth microdilution method with 96-well tissue culture plate. Minimum inhibitory concentration of the cinnamon bark oil against $L$. acidophilus was determined and that concentration was then incorporated into the liquid component of the GIC, and its compressive strength was evaluated. For compressive strength testing, teflon mold of $4 \mathrm{~mm}$ diameter and $6 \mathrm{~mm}$ height was used for the preparation of samples. The prepared specimens were stored in distilled water at $37^{\circ} \mathrm{C}$ for 24 hours in an incubator. After 24 hours, the samples were subjected to the universal testing machine at a speed of $1 \mathrm{~mm} /$ minute for compressive strength evaluation. The maximum load required to fracture the specimen was recorded.

Results: A volume of $20 \mu \mathrm{L} / \mathrm{mL}$ was found to be the MIC of the cinnamon bark oil against $L$. acidophilus. The mean compressive strengths of conventional and cinnamon bark oil-incorporated GIC revealed no significant difference.

Conclusion: Cinnamon bark oil has antibacterial property against $L$. acidophilus. Incorporation of $2 \% \mathrm{v} / \mathrm{v}$ cinnamon bark oil did not adversely affect the compressive strength of GIC.

Clinical significance: By incorporating this bacteriostatic agent to $\mathrm{GIC}$, the progress of caries and failure of restorations can be prevented by inhibiting the growth of $L$. acidophilus. Clinically, it can be used in cases of deep dentinal caries, early childhood caries, rampant caries, and patients with high caries index.

Keywords: Cinnamon, Compressive strength, Glass ionomer cement, Lactobacillus acidophilus.

How to cite this article: Bhanushali S, Srilatha KT, Girish MS. Antimicrobial Efficacy of Cinnamon Bark Oil on Lactobacillus acidophilus and its Effect on Compressive Strength of Glass Ionomer Cement. World J Dent 2017;8(3):164-170.

\footnotetext{
${ }^{1-3}$ Department of Paedodontics and Preventive Dentistry Jagadguru Sri Shivarathreeshwara Dental College and Hospital, Jagadguru Sri Shivarathreeshwara University, Mysuru Karnataka, India

Corresponding Author: Sheetal Bhanushali, Department of Paedodontics and Preventive Dentistry, Jagadguru Sri Shivarathreeshwara Dental College and Hospital, Jagadguru Sri Shivarathreeshwara University, Mysuru, Karnataka, India e-mail: sheetal.bhanushali15@gmail.com
}

Source of support: Nil

Conflict of interest: None

\section{INTRODUCTION}

Dental caries is an irreversible chronic infectious disease causing loss of tooth structure. The lack of the hermetic seal in the restored tooth and persistence of cariogenic bacteria can cause recurrent caries, leading to failure of restoration. One possible solution to overcome this is to use dental materials with an antibacterial property. ${ }^{1}$ Glass ionomer cement (GIC) is the mainstay of restoration in the primary dentition. Therapeutic benefit for this may therefore be achieved by combining antibacterial agents with GIC. However, the incorporation of antibacterial agents in restorative materials frequently interferes with its physical properties. Studying the physical properties combined with the antimicrobial effect after adding those agents is a valuable approach. ${ }^{2,3}$

These limitations can be overcome by the addition of an herbal antibacterial extracts. Among the plants, studied Cinnamomum zeylanicum Blume (cinnamon) is one of the most effective antibacterial agents. ${ }^{4,5}$

The purpose of this study was to determine the in vitro antibacterial effect of cinnamon bark oil on Lactobacillus acidophilus and its effect on compressive strength of GIC after incorporating the estimated concentration in a liquid component of GIC.

\section{MATERIALS AND METHODS}

This study was conducted in the Department of Paedodontics and Preventive Dentistry, Jagadguru Sri Shivarathreeshwara Dental College and Hospital, Mysuru, India, in two phases.

Antimicrobial Testing and MIC Determination of Cinnamon Bark Oil against L. acidophilus

Antimicrobial testing and MIC determination were done at the Department of Microbiology and Biochemistry, Jagadguru Sri Shivarathreeshwara Medical College and Hospital, Mysuru, India. The standard reference strain of L. acidophilus (TSP-Lal) was procured in freeze-dried vacuum ampoules from Triphase Pharmaceuticals Pvt. Ltd., Mysuru. These freeze-dried organisms were added to MRS broth to make a suspension of the culture. A few 
drops of the suspension were streaked on to MRS agar in a Petri plate as it is the selective media for L. acidophilus and were incubated at $37^{\circ} \mathrm{C}$ under aerobic conditions for 72 hours. The purity of the cultures was checked periodically by colony morphology and Gram staining.

The optical density (OD) of standardized bacterial suspension was adjusted to 0.1 which corresponds to 0.5 McFarland standard and $1.5 \times 10^{8} \mathrm{CFU} / \mathrm{mL}$. The antimicrobial activity of cinnamon bark oil was determined by broth microdilution method recommended by Clinical Laboratory Standards Institute using MRS broth. The 96-well tissue culture plates were used for testing various concentrations of cinnamon bark oil. Serial dilutions of the cinnamon bark oil samples ranging from 20 to $2.5 \mu \mathrm{L} /$ $\mathrm{mL}$ were prepared in 10\% dimethyl sulfoxide (DMSO); $0.2 \%$ chlorhexidine ( $\mathrm{CHX)}$ was used as a positive control, and MRS broth was used as a negative control.

A volume of $100 \mu \mathrm{L}$ of the prepared samples, at increasing concentrations of $2.5,5,10,20$, and $100 \mu \mathrm{L}$ of the prepared bacterial inoculums were added into the wells of 96-well tissue culture plate. Bacterial inoculum was added to all the wells except the negative control and then kept for incubation at $37^{\circ} \mathrm{C}$ for 24 hours.

After 24 hours of incubation, the antibacterial activity was recorded using visual confirmation and reading of absorbance using a multimode plate reader (EnSpire, Perkin Emler) at $600 \mathrm{~nm}$ wavelength. The OD values were then determined using the multimode plate reader. The lowest concentration of series which inhibited visible growth of bacteria was recorded. In the present study, $20 \mu \mathrm{L} / \mathrm{mL}$ dilution of cinnamon oil in DMSO exhibited considerable bacterial inhibition. Hence, it was considered as the minimum inhibitory concentration (MIC) for cinnamon bark oil against the L. acidophilus.

A volume of $20 \mu \mathrm{L} / \mathrm{mL}$ concentration of cinnamon bark oil was incorporated in the liquid component of GIC and was vortexed to obtain a homogeneous mixture

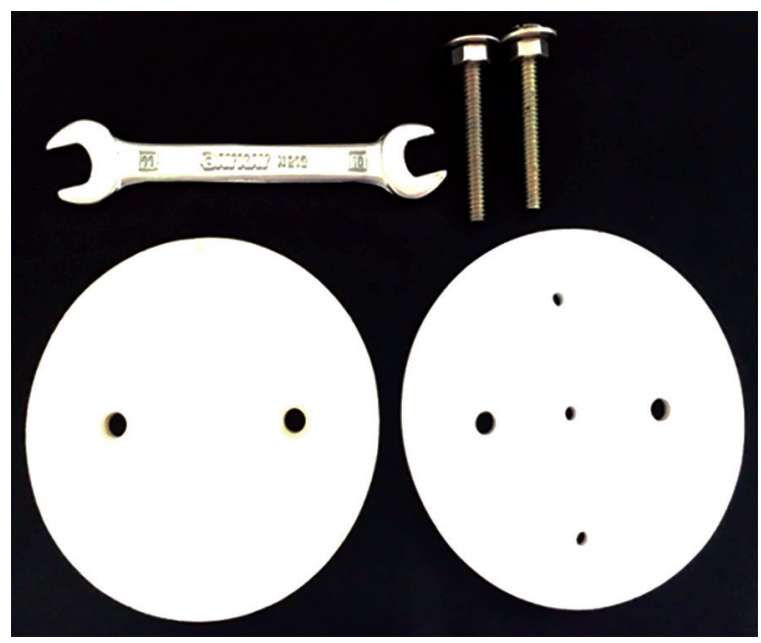

Fig. 1: Customized teflon jig for preparation of samples which was then used to prepare experimental GIC for its compressive strength evaluation.

\section{Testing Compressive Strength of Conventional and Cinnamon Bark Oil-incorporated GIC}

The samples for compressive strength were tested at the Department of Polymer Science and Technology, Sri Jayachamarajendra College of Engineering, Mysuru, India.

For the purpose of compressive strength evaluation, 13 specimens of each group were tested.

\section{Preparation of samples}

All the samples were prepared by a single operator using standardized teflon molds with inner dimensions of $6 \mathrm{~mm}$ thickness and $4 \mathrm{~mm}$ diameter (Fig. 1). The teflon molds used for preparing specimens were coated with petroleum jelly lubricant before the insertion of material to facilitate removal of hardened samples. The material was mixed according to the manufacturer's instructions and then inserted into the teflon molds (Fig. 2). The specimens were covered with acetate strips and sealed with knobs. The specimens were removed from the molds after the initial setting time (Fig. 3). A single coat of varnish was applied to each specimen. Specimens were kept in 100\% relative humidity for 60 minutes, and then they were stored in distilled water at $37^{\circ} \mathrm{C}$ for 24 hours in incubator as per International Standard Organization (ISO) and British Standards.

\section{Compressive Strength Testing}

For compressive strength testing, the specimens were placed with their flat ends up between the plates of universal testing machine. A compressive load was applied along the long axis at a crosshead speed of $1 \mathrm{~mm} / \mathrm{minute}$. The maximum force applied when the specimen fractured

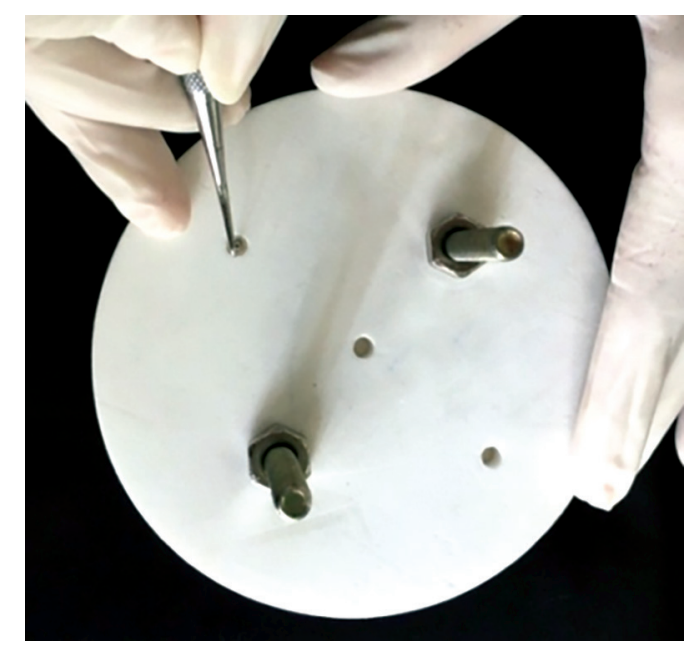

Fig. 2: Condensing the GIC into teflon mold 

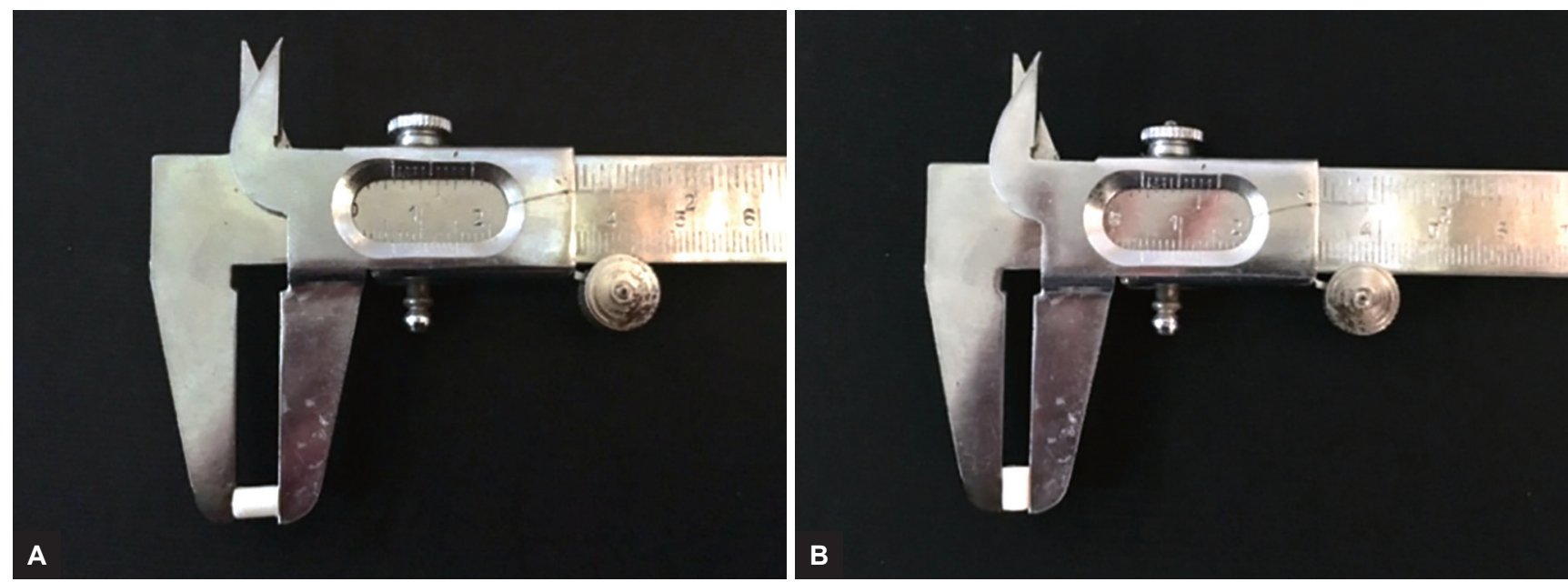

Figs 3 A and B: Prepared specimens of $6 \mathrm{~mm}$ height and $4 \mathrm{~mm}$ diameter

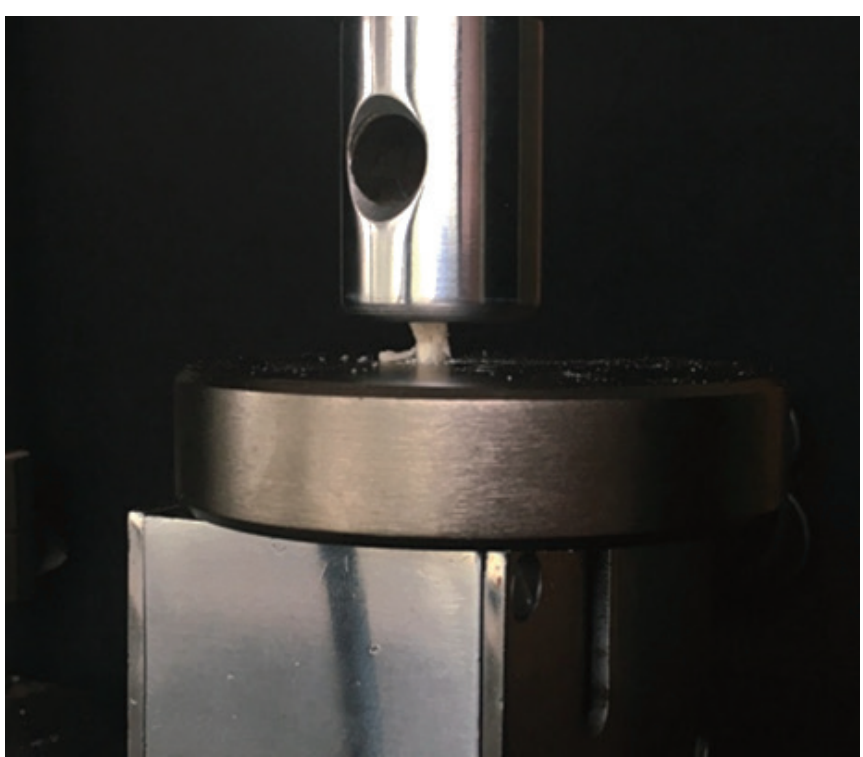

Fig. 4: Fracture of specimen postload application

was recorded (Figs 4 and 5), and the compressive strength was calculated by the following equation: 6,7

$$
\text { Compressive strength }=4 \frac{\mathrm{F}}{\pi \mathrm{d}^{2}}
$$

where $F$ is the maximum applied load $(\mathrm{N})$, and $d$ is the diameter of the specimen $(\mathrm{mm})$.

The data obtained were subjected to statistical analysis.

\section{Statistical Analysis}

Descriptive statistics was done to evaluate the mean of both the groups and independent $\mathrm{t}$-test was performed to compare the means of both the groups.

\section{RESULTS}

Minimum inhibitory concentration of cinnamon oil was found to be $20 \mu \mathrm{L} / \mathrm{mL}$ as this concentration was first to

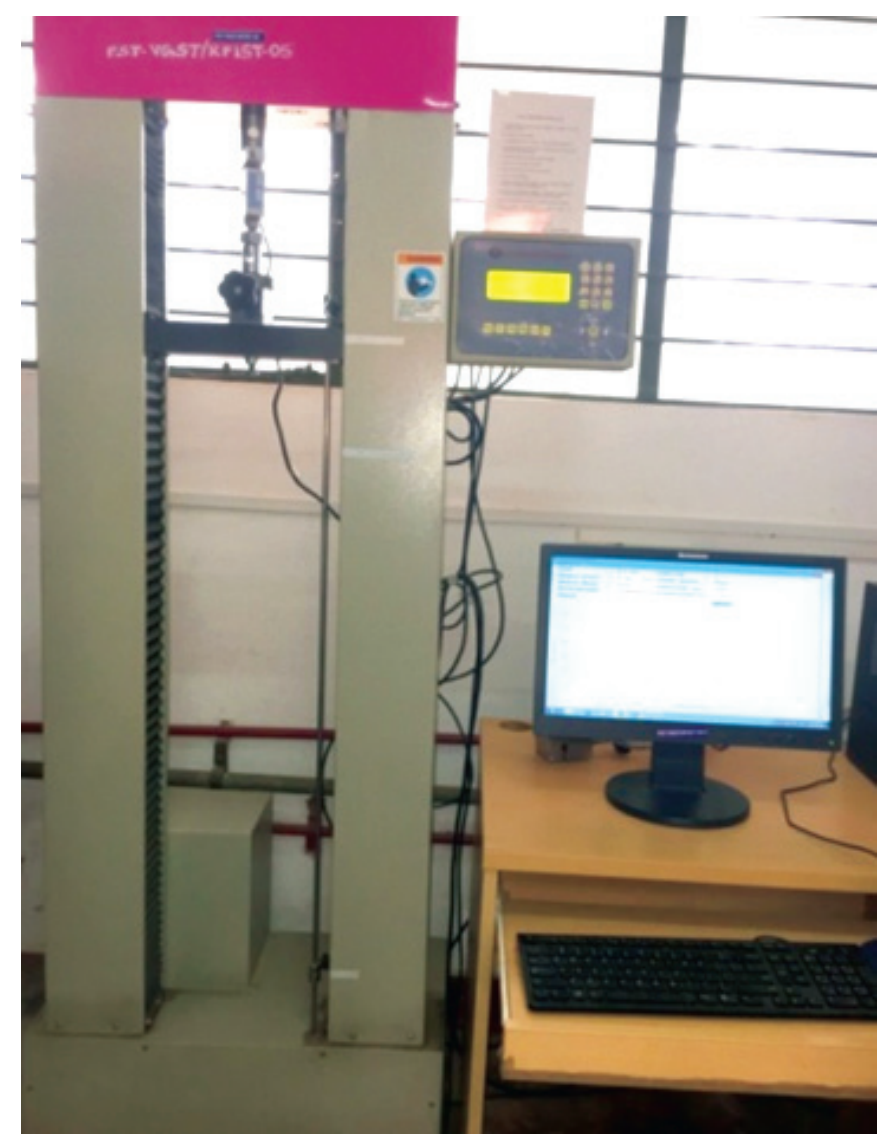

Fig. 5: Hounsfield universal testing machine with appropriate software to record all parameters

show visible decrease in the turbidity. The mean OD value for this group was least compared with the other concentration tested.

The mean compressive strength observed for conventional GIC and cinnamon bark oil-incorporated GIC was $61.21 \pm 4.59$ and $59.39 \pm 4.53 \mathrm{MPa}$ respectively, with a $p$-value of 0.32 ( $p>0.05)$, indicating a nonsignificant difference between the mean compressive strength values of conventional and cinnamon bark oil-incorporated GIC (Table 1 and Graph 1). 
Table 1: Intergroup compressive strength comparison of conventional and cinnamon bark oil-incorporated GIC

\begin{tabular}{llllll}
\hline & \multicolumn{3}{l}{$\begin{array}{l}\text { Mean } \\
\text { difference }\end{array}$} & t-value & $p$-value \\
\hline Conventional GIC & 13 & $61.21 \pm 4.59$ & 1.82 & 1.02 & 0.32 \\
Cinnamon bark & $1359.39 \pm 4.53$ & & & \\
oil-incorporated & & & & & \\
GIC & & & & & \\
\hline
\end{tabular}

SD: Standard deviation

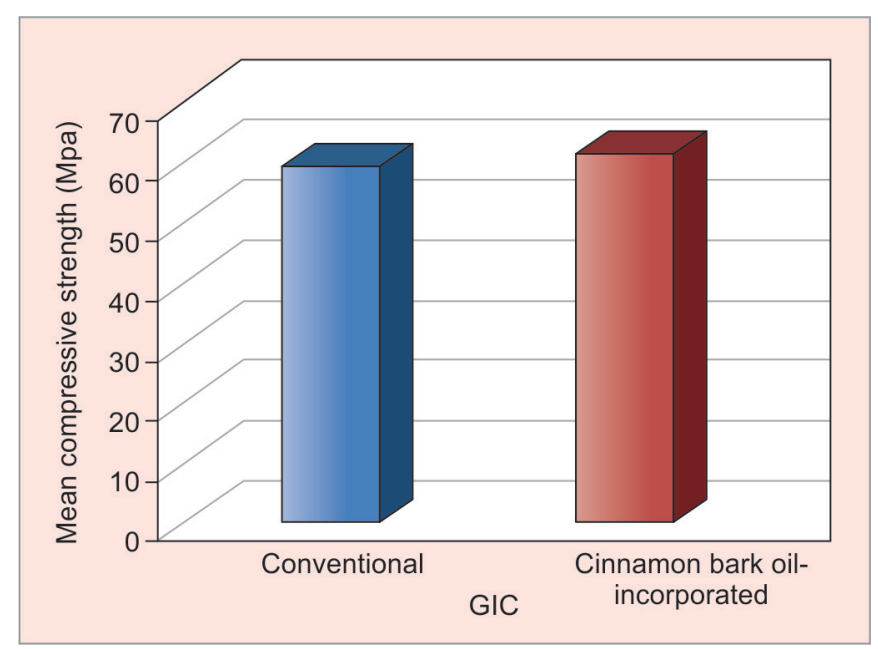

Graph 1: Mean compressive strength values for conventional glass and cinnamon bark oil-incorporated GIC

\section{DISCUSSION}

Dental caries is one of the most common chronic infectious diseases affecting the oral cavity. ${ }^{8}$ The microbial populations associated with dental caries are known to be highly complex and variable. According to Munson et $\mathrm{al}^{9}$ and Chhour et al, ${ }^{10}$ Streptococcus mutans and Lactobacillus species are dominant microorganism in the lesion of advanced caries, and these two are considered as a principle microorganism in the pathology of dental caries. S. mutans is the organism causing initiation of caries, whereas Lactobacillus causes progression of dental caries. van Strijp et $\mathrm{al}^{11}$ showed that lactobacilli in the dentin specimens were positively correlated with the lesion depth. They are now considered as secondary invaders rather than initiators of the caries process resulting in secondary caries. ${ }^{12}$ The Lactobacillus count is used to evaluate the carious risk. ${ }^{13,14}$ A strong correlation has been established between the Lactobacillus count and caries; the higher the decay-missing-filled index, the higher the number of children harboring a high Lactobacillus count. ${ }^{15}$ Since Lactobacillus is the common pathogenic organism causing secondary caries, ${ }^{12}$ there is a need of an antibacterial agent which can inhibit the growth of Lactobacillus, in turn preventing secondary caries. Thus, in this study, antibacterial effect and MIC of the cinnamon bark oil was determined against L. acidophilus.
Dental caries is a phenomenon causing irreversible loss of tooth structure. It is treated by the removal of the decayed tissue and replacing it with a biocompatible restorative material. In comparison with other materials used in clinical restorative dentistry, there is no better example, i.e., preferentially useful in consideration of pediatric dentistry than GIC. For children, these materials have offered an alternative that has insidiously become a "standard of care" in a variety of clinical indications for children. ${ }^{16}$ Glass ionomer cement has gained wide acceptance and popularity, mainly due to its ease of handling characteristics, chemical bonding to tooth structure, and fluoride release. ${ }^{17}$ However, according to Mazzaoui et al, ${ }^{18}$ the amount of fluoride released from GIC is not sufficient to show an antibacterial effect against caries-causing pathogens which can give rise to secondary caries. In addition, Yap et $\mathrm{al}^{19}$ showed that GIC does not promote an efficient antibacterial effect despite the presence of fluoride. The cariostatic effect of GIC is still doubtful. ${ }^{20}$ Clinical studies have shown that residual bacteria located under a GIC restoration are viable for up to 2 years. ${ }^{21,22}$ Therapeutic benefit may therefore be gained by incorporating antibacterial agent in the GIC. Previously, in the scientific literature, efforts have been made to improve the antibacterial effect of GIC by incorporating CHX,2,3,23,24 antibiotics, ${ }^{25}$ xylitol, ${ }^{24}$ and cetrimide. ${ }^{3}$ Incorporation of these agents improved the antimicrobial effect of the GIC on cariogenic microorganisms. ${ }^{26}$ However, Takahashi et $\mathrm{al}^{27}$ concluded that incorporation of $\mathrm{CHX}$ diacetate at $2 \%$ or greater concentration significantly decreased compressive strength and bond strength of GIC. Also, addition of the antibiotics, such as metronidazole, ciprofloxacin, and cefaclor, can give rise to possible antibiotic resistance. $^{3}$

These limitations can be overcome by incorporating a herbal antibacterial agent to the GIC cement. Natural products have been used for thousands of years in folk medicine, and they are believed to be the new source of antibacterial agents. ${ }^{28}$ One-fifth of the plants grown in India are used for medicinal purpose. Out of these plants, the bark of cinnamon is widely used as a spice. Cinnamon is reported for its antioxidant, antimicrobial, antidiabetic, and anti-inflammatory activity in scientific literature. It has been traditionally used to treat toothache and fight bad breath. ${ }^{29}$ In addition, Matan et $\mathrm{al}^{30}$ concluded that cinnamon bark oil is not harmful when consumed with food products and it inhibits the growth of yeast, molds, and bacteria. Jatan et $\mathrm{al}^{31}$ reported that cinnamaldehyde was the major component of cinnamon bark oil which is responsible for its antibacterial effect. It renders antibacterial effect by damaging the cell wall of the bacteria. ${ }^{4}$ Varalakshmi et $\mathrm{al}^{32}$ found that cinnamon bark extract had inhibited both Gram-positive and Gram-negative 
bacteria indicating broad spectrum inhibitory effect. It showed a greater inhibitory effect against Gram-positive bacteria; then, the Gram-negative bacteria demonstrating antibacterial effect is comparable with that of the standard drug ampicillin. In the study done by Gupta et $\mathrm{al}^{33}$ the antibacterial effect of cinnamon oil against oral pathogens was compared with the clove oil, and it was found that cinnamon oil was more effective compared with clove oil against all the species tested. In addition, Fani and Kohanteb ${ }^{34}$ determined the antibacterial activity of cinnamon and eucalyptus oil against the multidrugresistant S. mutans and methicillin-resistant Staphylococcus aureus, Candida albicans, and Candida glabrata, and it was found that all the tested species were sensitive to both the essential oils but cinnamon oil showed strong promising inhibitory activity even against the resistant bacteria compared with the eucalyptus oil.

Although antibacterial properties of cinnamon oil have been reported in the scientific literature, evidence on the action of the cinnamon oil on the pathogenic oral bacteria is still scarce. One of the objectives of this study is to improve the antibacterial effect of GIC by incorporating cinnamon bark oil in the liquid component of GIC to prevent the occurrence of secondary caries. Hence, attempt was made to determine the in vitro MIC of cinnamon bark oil against selected cariogenic pathogen, i.e., L. acidophilus.

The difficulties on the determination of the antibacterial activity of essential oils are well recognized, and this is mainly due to the volatile properties and insolubility of oils in water. According to Faleiro, ${ }^{35}$ these essential oils are hydrophobic in nature, and high viscosity of the oil causes an irregular distribution throughout the culture medium. Hence, in our study, the antibacterial effect of cinnamon bark oil against $L$. acidophilus was determined using a broth microdilution method, and it was found that cinnamon oil inhibited the growth of L. acidophilus. Optical density of the bacterial inoculums used for the study was adjusted to 0.1. In 96-well microtitre plate, equal volumes of bacterial inoculums with different concentrations $(2.5,5,10,20 \mu \mathrm{L} / \mathrm{mL})$ of cinnamon oil were added, and it was kept in the incubator for 24 hours. After 24 hours, the OD values of each the sample were determined using multimode plate reader. It was found that the mean OD value of the bacterial inoculums without cinnamon oil had increased to 0.49 , indicating growth of bacteria. Whereas the mean OD values of the samples containing bacterial broth with different concentrations of cinnamon oil were less compared with the OD value of the bacterial inoculum, indicating less turbid solution and hence inhibition of the growth of the L. acidophilus by cinnamon bark oil. The OD value of the bacterial broth with $20 \mu \mathrm{L} / \mathrm{mL}$ cinnamon oil concentration was found to be 0.19 , which is equivalent to the OD value of the standardized bacterial inoculum. In addition, $20 \mu \mathrm{L} / \mathrm{mL}$ was the first concentration to show visible decrease in the turbidity.

Percentage reduction in the OD values with the different concentrations of cinnamon bark oil in 10\% DMSO was also evaluated. These percentage reductions in OD values indicate the inhibition of the growth of bacteria by the respective concentration of the cinnamon bark oil. Maximum percentage reduction in the growth of bacteria is $61.07 \%$, which was shown by $20 \mu \mathrm{L} / \mathrm{mL}$ concentration.

Hence, $20 \mu \mathrm{L} / \mathrm{mL}$, i.e., $2 \%$, of cinnamon bark oil was added per milliliter of the liquid component of experimental GIC.

While the presence of an antibiotic in a dental material can be effective against oral pathogens, it is necessary that any additive should not adversely affect the physical and mechanical properties of a restorative material. Hence, in our study, after incorporating the cinnamon bark oil in the liquid component of GIC, the most common physical property mentioned in the literature, i.e., compressive strength, was evaluated, and it was compared with that of conventional GIC.

For the compressive strength testing of the specimens of both the groups, customized teflon jig was made, in which three cylindrical molds were prepared with a dimension of $4 \mathrm{~mm}$ diameter and $6 \mathrm{~mm}$ height according to ISO 7489:1986 specifications. ${ }^{36}$ These dimensions are in accordance with the dimensions used by Yli-Urpo et $\mathrm{al}^{37}$ Mallmann et al, ${ }^{7}$ and Mohammed and Raghad. ${ }^{38}$ Specimens were kept in 100\% relative humidity for $60 \mathrm{~min}$, and then, they were stored in distilled water at $37^{\circ} \mathrm{C}$ for a period of 24 hours in incubator as per ISO and British Standards.

The mean compressive strength for conventional GIC was $61.21 \pm 4.59 \mathrm{MPa}$. The compressive strength values ranged from 54.66 to 69.41 . The compressive strength values of conventional GIC obtained in this study are in accordance with the values obtained by Mallmann et $\mathrm{al}^{7}$ and Khaghani et $\mathrm{al}^{39}$ with the same specimen dimension.

The mean compressive strength value of cinnamon bark oil-incorporated GIC was $59.39 \pm 4.53 \mathrm{MPa}$. The compressive strength values ranged from 53.17 to 69.72 $\mathrm{MPa}$, which are comparable to the compressive strength of the conventional GIC.

Means of both the groups were compared using independent $t$-test. The mean difference of both the group was found to be $1.81 \mathrm{MPa}$, with $\mathrm{p}$-value of 0.32 ( $\mathrm{p}>0.05)$ indicating a nonsignificant difference between the mean compressive strength of conventional and cinnamon bark oil-incorporated GIC.

In this study, the compressive strength values of cinnamon bark oil-incorporated GIC and conventional GIC are comparable, indicating that incorporation of $2 \%$ 
$\mathrm{v} / \mathrm{v}$ cinnamon bark oil did not affect the compressive strength of GIC.

Hence, cinnamon bark oil containing GIC can be beneficial clinically as Lactobacillus is the organism responsible for the progression of the carious lesion and it is the main organism causing secondary caries. By incorporating this bacteriostatic agent to GIC, the progress of caries and failure of restorations can be prevented by inhibiting the growth of L. acidophilus. Clinically, it can be used in the cases of deep dentinal caries, early childhood caries, rampant caries, and patients with high caries index.

However, intraoral variables, such as normal masticatory stress, moisture, and operator inconsistencies, are not taken into consideration in the present study. Therefore, further studies are necessary to test the long-term stability of this material.

\section{CONCLUSION}

Within the limitations of the present study, we can conclude that addition of the $2 \% \mathrm{v} / \mathrm{v}$ of cinnamon bark oil did not jeopardize with the basic physical property of the material, thus $2 \% \mathrm{v} / \mathrm{v}$ cinnamon bark oil can be used as a potential additive to gas-liquid chromatography. However, its effect on various other parameters, such as shelf life, stability, salivary saturation, and cinnamon oil release, needs further elucidation by other more sensitive modalities.

\section{CLINICAL SIGNIFICANCE}

By incorporating this bacteriostatic agent to GIC, the progress of caries and failure of restorations can be prevented by inhibiting the growth of L. acidophilus. Clinically, it can be used in the cases of deep dentinal caries, early childhood caries, rampant caries, and patients with high caries index.

\section{ACKNOWLEDGMENT}

Authors would like to thank Triphase Pharmaceuticals Pvt, Ltd., Mysuru, for providing their materials used in this study.

\section{REFERENCES}

1. Bergenholtz G, Cox CF, Loesche WJ, Syed SA. Bacterial leakage around dental restorations: its effect on the dental pulp. J Oral Pathol 1982 Dec;11(6):439-450.

2. Sanders BJ, Gregory RL, Moore K, Avery DR. Antibacterial and physical properties of resin modified glass-ionomers combined with chlorhexidine. J Oral Rehabil 2002 Jun;29(6): 553-558.

3. Deepalakshmi M, Poorni S, Miglani R, Rajamani I, RamachandranS. Evaluation of the antibacterial and physical properties of glass ionomer cements containing chlorhexidine and cetrimide: an in-vitro study. Indian J Dent Res 2010 OctDec;21(4):552-556.
4. Unlu M, Ergene E, Unlu GV, Zeytinoglu HS, Vural N. Composition, antimicrobial activity and in vitro cytotoxicity of essential oil from Cinnamomum zeylanicum Blume (Lauraceae). Food Chem Toxicol 2010 Nov;48(11):3274-3280.

5. Chaudhari LK, Jawale BA, Sharma S, Sharma H, Kumar CD, Kulkarni PA. Antimicrobial activity of commercially available essential oils against Streptococcus mutans. J Contemp Dent Pract 2012 Jan;13(1):71-74.

6. Prabhakar AR, Maganti R, Mythri P, Naik SV. A traditional way to combat against Streptococcus mutans. Int J Ayurvedic Med 2016 Apr;7(1):37-43.

7. Mallmann A, Ataíde JC, Amoedo R, Rocha PV, Jacques LB. Compressive strength of glass ionomer cements using different specimen dimensions. Braz Oral Res 2007 Jul-Sep;21(3): 204-208.

8. Anusavice KJ. Dental caries: risk assessment and treatment solutions for an elderly population. Compend Contin Educ Dent 2002 Oct;23(10 Suppl):12-20.

9. Munson MA, Banerjee A, Watson TF, Wade WG. Molecular analysis of the microflora associated with dental caries. J Clin Microbiol 2004 Jul;42(7):3023-3029.

10. Chhour KL, Nadkarni MA, Byun R, Martin FE, Jacques NA, Hunter N. Molecular analysis of microbial diversity in advanced caries. J Clin Microbiol 2005 Feb;43(2):843-849.

11. van Strijp AJ, van Steenbergen TJ, ten Cate JM. Bacterial colonization of mineralized and completely demineralized dentine in situ. Caries Res 1997;31(5):349-355.

12. Tanzer JM, Livingston J, Thompson AM. The microbiology of primary dental caries in humans. J Dent Educ 2001 Oct;65(10):1028-1037.

13. Crossner CG. Salivary Lactobacillus counts in the prediction of caries activity. Community Dent Oral Epidemiol 1981 Aug;9(4):182-190.

14. Scheinin A, Pienihäkkinen K, Tiekso J, Holmberg S, Fukuda M, Suzuki A. Multifactorial modeling for root caries prediction: 3-year follow-up results. Community Dent Oral Epidemiol 1994 Apr;22(2):126-129.

15. Badet $C$, Thebaud NB. Ecology of lactobacilli in the oral cavity: a review of literature. Open Microbiol J 2008;2:38-48.

16. Berg JH. Glass ionomer cements. Pediatr Dent 2002 Sep-Oct; 24(5):430-438.

17. Lienfelder KF. Glass ionomer: current clinical development. JADA 1993;124:63-65.

18. Mazzaoui SA, Burrow MF, Tyas MJ. Fluoride release from glass ionomer cements and resin composites coated with a dentin adhesive. Dent Mater 2000 May;16(3):166-171.

19. Yap AU, Khor E, Foo SH. Fluoride release and antibacterial properties of new-generation tooth-colored restoratives. Oper Dent 1999 Sep-Oct;24(5):297-305.

20. van Amerongen WE. Dental caries under glass ionomer restorations. J Public Health Dent 1996;56(3) Spec No:150-154.

21. Weerheijm KL, de Soet JJ, van Amerongen WE, de Graaff J. The effect of glass-ionomer cement on carious dentine: an in vivo study. Caries Res 1993;27(5):417-423.

22. Weerheijm KL, Kreulen CM, de Soet JJ, Groen HJ, van Amerongen WE. Bacterial counts in carious dentine under restorations: 2-year in vivo effects. Caries Res 1999;33(2): 130-134.

23. Marti LM, Mata Md, Ferraz-Santos B, Azevedo ER, Giro EM, Zuanon AC. Addition of chlorhexidine gluconate to a glass ionomer cement: a study on mechanical, physical and antibacterial properties. Braz Dent J 2014 Jan-Feb;25(1):33-37. 
24. Prabhakar AR, Agarwal S, Basappa N. Comparative evaluation of antibacterial effect and physical properties of conventional glass-ionomer cement containing $1 \%$ chlorhexidine and 1\% xylitol. Int J Oral Health Sci 2014 Jul;4(2):63-69.

25. de Castilho AR, Duque C, Negrini Tde C, Sacono NT, de Paula AB, Sacramento PA, de Souza Costa CA, Spolidorio DM, Puppin-Rontani RM. Mechanical and biological characterization of resin-modified glass-ionomer cement containing doxycycline hyclate. Arch Oral Biol 2012;57(2): 131-138.

26. Jedrychowski JR, Caputo AA, Kerper S. Antibacterial and mechanical properties of restorative materials combined with chlorhexidines. J Oral Rehabil 1983 Sep;10(5):373-381.

27. Takahashi Y, Imazato S, Kaneshiro AV, Ebisu S, Frencken JE, Tay FR. Antibacterial effects and physical properties of glass-ionomer cements containing chlorhexidine for the ART approach. Dent Mater 2006 Jul;22(7):647-652.

28. Al-Duboni G, Osman MT, Al-Naggar R. Antimicrobial activity of aqueous extracts of cinnamon and ginger on two oral pathogens causing dental caries. RJPBCS 2013 Jul;4(3):957-965.

29. Jakhetia V, Pate R, Khatri P. Cinnamon: a pharmacological review. J Adv Sci Res 2010;1(2):19-23.

30. Matan N, Rimkeeree H, Mawson AJ, Chompreeda P, Haruthaithanasan V, Parker M. Antimicrobial activity of cinnamon and clove oils under modified atmosphere conditions. Int J Food Microbiol 2006 Mar;107(2):180-185.

31. Jatan IB, Moharam KBA, Santhanam J. Correlation between chemical composition and amtifungal activity of the essential oils of eight Cinnamomum species. Pharm Biol 2001;46(6): 406-412.
32. Varalakshmi B, Anand AV, Karpagam T, Bai JS, Manikandan R. In vitro antimicrobial and anticancer activity of Cinnamomum zeylanicum Linn bark extracts. Int J Pharm Sci Res 2014; 6(1):12-18.

33. Gupta C, Kumari A, Garg AP, Catanzaro R, Marotta F. Comparative study of cinnamon oil and clove oil on some oral microbiota. Acta Biomed 2011 Dec;82(3):197-199.

34. Fani MM, Kohanteb J. Inhibitory activity of Cinnamon zeylanicum and Eucalyptus globulus oils on Streptococcus mutans, Staphylococcus aureus, and Candida species isolated from patients with oral infections. Shiraz Univ Dent J 2011 Jan;11:14-22.

35. Faleiro, ML. The mode of antibacterial action of essential oils. Science against microbial pathogens: communicating current research and technological advances-Formatex. Spain: Formatex Research Center; 2011. p. 1143-1156.

36. International Organization for Standardization. ISO 7489. Dental Glass Polyalkenoate Cements. Geneva: The Organization; 1986.

37. Yli-Urpo H, Lassila LV, Närhi T, Vallittu PK. Compressive strength and surface characterization of glass ionomer cements modified by particles of bioactive glass. Dent Mater 2005 Mar;21(3):201-209.

38. Mohammed R, Raghad A. Assessment of consistency and compressive strength of glass ionomer reinforced by different amount of hydroxyapatite. Restor Dent 2008;20(1):16-20.

39. Khaghani M, Doostmohammadi A, Alizadeh S. Investigation the compressive strength of glass ionomer cement containing hydroxyapatite nano and micro particles. Aust J Biotechnol Bioeng 2016;3(3):1-4. 